\title{
SÍNTESE E AVALIAÇÃo DA PROPRIEDADE REGULADORA DE CRESCIMENTO VEGETAL DE COMPOSTOS INDÓLICOS DERIVÁDOS DO SAFROL
}

\author{
Irineu Marchi* \\ Escola Agrotécnica Federal de Rio do Sul, Estrada do Redentor, 5665, 89160-000 Rio do Sul - SC, Brasil \\ Ricardo Andrade Rebelo, Flávia A. Fernandes da Rosa e Riceli A. Maiochi \\ Departamento de Química, Universidade Regional de Blumenau, 89010-971 Blumenau - SC, Brasil
}

Recebido em 14/7/05; aceito em 28/8/06; publicado na web em 26/3/07

\begin{abstract}
SYNTHESIS AND EVALUATION OF THE PLANT GROWTH REGULATOR PROPERTY OF INDOLIC COMPOUNDS DERIVED FROM SAFROLE. The present work describes the use of piperonal, a derivative of the secondary metabolite safrole, for the synthesis of new 5,6-methylenedioxysubstituted indole carboxylic acids structurally related to the indol-3-yl-acetic acid (AIA, I). The route comprises six steps beginning with piperonal with an overall yield of 19\%. Compound IX was tested towards its plant growth regulator properties in bioassays specific for auxine activity. The in vitro assays were performed in a germination chamber and were of two types: root growth in germinated seeds of Lactuca sativa, Cucumbis sativus and Raphanus sativus and peciole biotest using Phaseolus vulgaris.
\end{abstract}

Keywords: indolecarboxylic acids; piperonal; plant growth regulator.

\section{INTRODUÇÃO}

Em plantas, assim como em animais, muitos processos bioquímicos e físiológicos são controlados por hormônios. Os hormônios são produzidos em um sítio da planta e translocados para outros sítios para alterar o crescimento e o desenvolvimento. O hormônio natural e outros materiais são essencialmente "mensageiros químicos", influenciando em vários estágios do desenvolvimento da planta ${ }^{1}$.

A auxina natural mais importante presente na maioria das plantas é o ácido indol-3-il-acético (AIA - I). Recentemente foi preparado um novo regulador de crescimento vegetal, o ácido-5,6-metilenodioxindol-3-il-acético (II), que demonstrou atividade auxínica ${ }^{2}$.
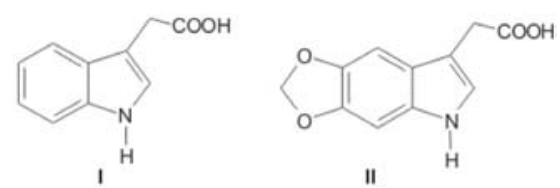

Considerando-se a importância da síntese de substâncias que possuem similaridade com hormônios vegetais e sua aplicação na agricultura, este trabalho teve por objetivo sintetizar novos compostos indólicos 5,6-metilenodioxissubstituídos e avaliar a propriedade reguladora de crescimento vegetal dos compostos sintetizados, análogos ao II, empregando ensaios in vitro.

\section{PARTE EXPERIMENTAL}

Os reagentes e solventes empregados foram de pureza analítica e procedência Aldrich, Merck, Carlo Erba, Sigma, Riedel-deHaên, Vetec, Reagen, Grupo Químico e Nuclear. Os solventes orgânicos foram secos e/ou purificados quando necessário, de acordo com os métodos tradicionais descritos na literatura ${ }^{3}$. $\mathrm{O}$ cloreto de fosforila foi submetido à destilação simples e à pressão normal previamente ao seu uso.

\footnotetext{
*e-mail: marchi@softhouse.com.br
}

Os espectros no IV foram obtidos em espectrofotômetro PerkinElmer modelo FT-IR 16PC, empregando-se pastilhas de $\mathrm{KBr}$ ou filme em cela de $\mathrm{NaCl}$. As análises espectroscópicas de $\mathrm{RMN}{ }^{1} \mathrm{H}$ e ${ }^{13} \mathrm{C}$ foram realizadas em aparelho Brucker de 200 e $50 \mathrm{MHz}$, respectivamente. Os deslocamentos químicos são dados em partes por milhão (ppm), utilizando-se tetrametilsilano (TMS) como referência interna. As análises elementares foram realizadas em analisador de $\mathrm{C}, \mathrm{H}$, N Perkin-Elmer 2400. As análises de massas foram realizadas em espectrômetro CGMS-QP-2000-A Shimadzu com impacto de elétrons em $70 \mathrm{ev}$. As medidas de ponto de fusão foram efetuadas em aparelho de chapa quente tipo Koffler (MicroQuímica APF-301) e não foram corrigidas. No acompanhamento de reações foi empregada a técnica de CCD, utilizando-se como suporte sílica gel $60 \mathrm{GF}_{254}$ com os compostos visualizados por irradiação UV (254 nm) e vapor de iodo, quando necessário. Esta técnica também foi empregada para avaliar o grau de pureza dos reagentes e produtos. Alguns compostos foram purificados pela técnica de cromatografia em coluna, utilizando-se como suporte sílica gel 70-230 mesh e diferentes eluentes, indicados nos procedimentos.

Para a obtenção de novos reguladores indólicos de crescimento vegetal contendo o substituinte metilenodioxi, foi realizada a síntese do ácido 5,6-metilenodioxindol-3-il-metanóico (IX) empregando como precursor o produto comercial piperonal ${ }^{4-11}$. Os compostos sintetizados foram obtidos em bom rendimento e caracterizados por análises espectroscópicas no IV, RMN ${ }^{1} \mathrm{H}$ e ${ }^{13} \mathrm{C}$, massas e análise elementar.

\section{3,4-metilenodioxi- $\beta$-nitroestireno (IV)}

Uma mistura de 3,4-metilenodioxibenzaldeído (10 g, 66,7 mmol), nitrometano $(11 \mathrm{~mL})$, acetato de amônio $(13,9 \mathrm{~g})$ e ácido acético glacial $(200 \mathrm{~mL})$ foi refluxada durante $4 \mathrm{~h}$ à temperatura de $120{ }^{\circ} \mathrm{C}$ (inicialmente a mistura era incolor e após $30 \mathrm{~min}$ tornou-se alaranjada). A mistura foi resfriada à temperatura ambiente e vertida em água a $0{ }^{\circ} \mathrm{C}$. O sólido amarelo formado foi filtrado em funil de Büchner, lavado com água gelada e secado em estufa a vácuo a $70{ }^{\circ} \mathrm{C}$. O produto foi obtido suficientemente puro com rendimento 
de 73\%; pf 159,2-160,9 ${ }^{\circ} \mathrm{C}$ (Lit. $\left..^{12} 159-161{ }^{\circ} \mathrm{C}\right)$. IV (KBr, v/cm $\left.{ }^{-1}\right)$ : 3420 (NH), 1492 (NO), 1334 (NO), 1268 (COC); RMN ${ }^{1} \mathrm{H}$ (acetona-d $\left.{ }_{6}, \delta\right): 6,13(\mathrm{~s}, 2 \mathrm{H}) ; 6,99(\mathrm{~d}, J$ 7, $96 \mathrm{~Hz}, 1 \mathrm{H}) ; 7,37(\mathrm{~d}, J$ 7,99 Hz, $1 \mathrm{H}) ; 7,38(\mathrm{~s}, 1 \mathrm{H}) ; 7,9(\mathrm{~d}, J 13,55 \mathrm{~Hz}, 1 \mathrm{H}) ; 8,05(\mathrm{~d}, J 13,54 \mathrm{~Hz}, 1 \mathrm{H})$. RMN ${ }^{13} \mathrm{C}$ (acetona-d ${ }_{6}$ ): $\delta 102,5 ; 106,9 ; 109,0 ; 124,1 ; 128,6 ; 135,3$; 139,$0 ; 148,7 ; 151,3$; MS: $m / z$ (intensidade relativa/\%) $193\left(\mathrm{M}^{+}\right.$, 100\%), 146 (100\%), 117 (20\%), 89 (100\%), 65 (26\%), 63 (90\%) Anal. Calcd. para $\mathrm{C}_{9} \mathrm{H}_{7} \mathrm{NO}_{4}(\%)$ : C55,96; $\mathrm{H3}, 65 ; \mathrm{N} 7,26$; encontrado C55,74; H3,67; N7,26.

\section{$O$-nitro-3,4-metilenodioxi- $\beta$-nitroestireno (V)}

Uma mistura de ácido nítrico concentrado $(17,5 \mathrm{~mL})$ e ácido acético glacial $(13,3 \mathrm{~mL})$ foi resfriada a $5{ }^{\circ} \mathrm{C}$ e adicionada gota a gota a um frasco mantido em banho de gelo contendo 3,4metilenodioxi- $\beta$-nitroestireno $(5,0 \mathrm{~g})$ sob agitação magnética. Ao término da adição, o banho de gelo foi removido e a mistura mantida sob agitação por $3 \mathrm{~h}$ adicionais, quando então foi vertida em gelo e água. O sólido formado foi filtrado em funil de Büchner, lavado com água gelada até neutralização e secado em estufa a vácuo. A recristalização com etanol forneceu o produto puro em $94 \%$ de rendimento; pf $121-122{ }^{\circ} \mathrm{C}$ (Lit. $\left.{ }^{12} 121-122{ }^{\circ} \mathrm{C}\right)$. IV (KBr): $v_{\max } / \mathrm{cm}$ $3450(\mathrm{NH}), 1506$ (CNO), 1324 (CNO) $1270 \mathrm{~cm}^{-1}$ (COC); RMN ${ }^{1} \mathrm{H}$ $\left(200 \mathrm{MHz}\right.$, Acetona-d $\left.\mathrm{d}_{6}\right) \delta$ 6,35 (s, 2H), 7,43 (s, 1H), 7,69 (s, 1H), $7,91$ (d, $J 13,42 \mathrm{~Hz}, 1 \mathrm{H}), 8,49$ (d, $J 13,42 \mathrm{~Hz}, 1 \mathrm{H}) ; \mathrm{RMN}{ }^{13} \mathrm{C}(50$ MHz), Acetona-d $) \delta 105,6 ; 106,9 ; 108,9 ; 123,2 ; 136,3 ; 141 ; 153,7$; MS: $m / z$ (intensidade relativa) $238\left(\mathrm{M}^{+}, 15 \%\right), 206(2 \%), 162(25 \%)$, 161 (20\%), 136 (55\%), 106 (45\%), 78 (47\%), 76 (70\%), 62 (100\%). Anal. Calcd., para $\mathrm{C}_{9} \mathrm{H}_{6} \mathrm{~N}_{2} \mathrm{O}_{6}$; $\mathrm{C} 45,39 \%, \mathrm{H} 2,53 \%$, N11,76\%, encontrado $\mathrm{C} 45,78 \%, \mathrm{H} 2,67 \%$, N11,65\%.

\section{5,6-metilenodioxindol (VI) via ciclização redutiva}

\section{Procedimento 1}

Uma mistura de $o$-nitro-3,4-metilenodioxi- $\beta$-nitroestireno $(1,0$ g; 4,2 mmol), sílica gel 60 para coluna cromatográfica $(5,6$ g, 70$230 \mathrm{mesh})$, ferro em pó $(3,4 \mathrm{~g})$, ácido acético glacial $(29,2 \mathrm{~mL})$, benzeno $(10,6 \mathrm{~mL})$ e cicloexano $(32,0 \mathrm{~mL})$ foi refluxada durante $4 \mathrm{~h}$ sob atmosfera de nitrogênio. A mistura foi resfriada a $25^{\circ} \mathrm{C}$, diluída em diclorometano e filtrada. O sólido foi lavado com uma solução $10 \%$ de éter etílico em diclorometano; as fases orgânicas combinadas foram lavadas com metabissulfito de sódio (10\%), bicarbonato de sódio (20\%), cloreto de sódio (20\%) e tratadas com sulfato de magnésio. A fase orgânica seca foi filtrada e o solvente foi removido por evaporação sob pressão reduzida. Depois foi adicionado n-hexano, esfriado e devidamente isolado, o sólido escuro formado foi purificado por diversas lavagens com diclorometano e posterior adição de n-hexano fornecendo o indol VI puro em $68 \%$ de rendimento e pf $108,7-109,2^{\circ} \mathrm{C}$, estando de acordo com o citado na literatura ${ }^{12}$ (p.f $108-110^{\circ} \mathrm{C}$ ).

\section{Procedimento 2}

Uma mistura de $o$-nitro-3,4-metilenodioxi- $\beta$-nitroestireno $(0,2$ $\mathrm{g}, 0,8 \mathrm{mmol})$, catalisador $\mathrm{Pd} / \mathrm{C} 10 \%(1,1 \mathrm{~g})$, etanol absoluto $(24,0$ $\mathrm{mL})$ e cicloexano $(1,0 \mathrm{~mL})$ foi refluxada durante $3 \mathrm{~h}$. A mistura foi esfriada e filtrada e o sólido lavado com uma solução $10 \%$ de éter etílico em diclorometano; as fases orgânicas combinadas foram lavadas com metabissulfito de sódio (10\%), bicarbonato de sódio (20\%), cloreto de sódio $(20 \%)$ e tratadas com sulfato de magnésio. A fase orgânica seca foi filtrada e o solvente foi removido por evaporação sob pressão reduzida. Depois foi adicionado n-hexano, esfriado e devidamente isolado, o sólido escuro formado foi purificado por diversas lavagens com dicloro metano e posterior adição de n-hexano fornecendo o indol VI puro em $17 \%$ de rendimento; $\mathrm{pf}=108,7$ $109,2{ }^{\circ} \mathrm{C}$ (Lit. ${ }^{12} 108-110{ }^{\circ} \mathrm{C}$ ); IV (KBr): $v_{\max } / \mathrm{cm}^{-1}, 3410(\mathrm{NH}), 3072$ (CH), 1206 (COC); RMN ${ }^{1} \mathrm{H}\left(200 \mathrm{MHz}, \mathrm{CDCl}_{3}\right) \delta 5,92(\mathrm{~s}, 2 \mathrm{H}), 6,42$ (s, 1H), 6,84(s, 1H), 7,00(s, 1H), 7,06 (s, 1H), 8,0 (s, 1H, NH); RMN $\left.{ }^{13} \mathrm{C}(50 \mathrm{MHz}), \mathrm{CDCl}_{3}\right) \delta 91,8 ; 99,1 ; 100,5 ; 102,8 ; 121,6 ; 122,7 ; 130,6$; 143; 144,9; MS: $m / z$ (intensidade relativa) $161\left(\mathrm{M}^{+}, 100 \%\right), 103$ (38\%), 76 (33\%), 50 (23\%). Anal. Calcd., para $\mathrm{C}_{9} \mathrm{H}_{7} \mathrm{NO}_{2} \mathrm{C} 67,10 \%$, $\mathrm{H} 4,34 \%$, N8,69\%; encontrado C67,32\%, H4,23\%, N8,56\%.

\section{5,6-metilenodioxindol-3-il-formaldeído (VII)}

$N, N$-dimetilformamida $(2,0 \mathrm{~mL})$ foi resfriada à temperatura de $10-20{ }^{\circ} \mathrm{C}$ e tratada gota a gota com tricloreto de fosforila $(0,6 \mathrm{~mL})$. Após 15 min, uma solução de 5,6-metilenodioxindol (1,0 g, $6 \mathrm{mmol})$ em $N, N$-dimetilformamida $(0,3 \mathrm{~mL})$ foi adicionada lentamente à mistura previamente preparada, mantendo-se a temperatura entre 20-30 ${ }^{\circ} \mathrm{C}$. A mistura reacional foi agitada durante $2 \mathrm{~h}$ e vertida em gelo picado. À solução resultante foi adicionada lentamente uma solução de hidróxido de sódio (1,1 g; $28 \mathrm{mmol})$ em água $(5,4 \mathrm{~mL})$. O sólido formado foi filtrado em funil de Büchner, lavado com água gelada e secado em estufa a vácuo. O sólido foi purificado por cromatografia em coluna utilizando como eluente diclorometano, fornecendo o produto puro em $74 \%$ de rendimento; p.f $=$ 222,2 ${ }^{\circ} \mathrm{C}$ com decomposição. IV (KBr): $v_{\max } / \mathrm{cm}^{-1}, 3194(\mathrm{NH}), 2886$ (CH), 1632 (CO), 1294 (COC); RMN ${ }^{1} \mathrm{H}\left(200 \mathrm{MHz}, \mathrm{CDCl}_{3}\right) \delta 5,99$ (s, 2H), 7,01 (s, 1H), 7,60 (s, 1H), 8,01(s, 1H), 9,93 (s, 1H, CHO), $\left.11,0(\mathrm{~s}, 1 \mathrm{H}, \mathrm{NH}) ; \mathrm{RMN}{ }^{13} \mathrm{C}(50 \mathrm{MHz}), \mathrm{CDCl}_{3}\right) \delta 93,66 ; 100,67$; 101,$88 ; 119,50 ; 120,32 ; 133,12 ; 136,14 ; 145,75 ; 146,87 ; 185,24$; MS: $m / z$ (intensidade relativa) $289\left(\mathrm{M}^{+}, 100 \%\right), 160(13 \%), 76$ (33\%), 50 (30\%). Anal. Calcd., para $\mathrm{C}_{10} \mathrm{H}_{7} \mathrm{NO}_{3} ; \mathrm{C} 63,48 \%, \mathrm{H} 3,72 \%$, N7,40\%, encontrado C,63,10\%; H, 3,82\%; N, 7,54\%.

\section{3-ciano-5,6-metilenodioxindol (VIII)}

5,6-metilenodioxindol-3-il-formaldeído (200 mg; $67 \mathrm{mmol}) \mathrm{em}$ DMF $(1,0 \mathrm{~mL})$ foi aquecido a refluxo, quando então foi adicionada gota a gota uma solução de cloridrato de hidroxilamina $(120 \mathrm{mg}, 1$ mmol) em DMF (1,0 mL). A solução resultante foi refluxada por $7 \mathrm{~h}$, sendo posteriormente resfriada em banho de gelo. Foi adicionada água lentamente, que promoveu a precipitação do sólido. Este foi isolado por filtração em funil de Büchner, lavado com água e secado em estufa a vácuo. $\mathrm{O}$ produto nitrila foi obtido em rendimento de $74 \%$; $\mathrm{pf}=$ 219,4-224,1 ${ }^{\circ} \mathrm{C}$; IV (KBr): $v_{\max }$ /cm $^{-1}, 3269(\mathrm{NH}), 2218(\mathrm{CN})$ e 1223 (COC); RMN ${ }^{1} \mathrm{H}(200 \mathrm{MHz}$, Acetona-d $) \delta 2,87$ (s, 2H), 5,96 (s, H), $6,99(\mathrm{~s}, 1 \mathrm{H}), 7,84(\mathrm{~s}, 1 \mathrm{H}), 11,00(\mathrm{~s}, 1 \mathrm{H}, \mathrm{NH})$; RMN ${ }^{13} \mathrm{C}(50 \mathrm{MHz}$, Acetona-d $) \delta 87,35 ; 94,33 ; 98,23 ; 102,18 ; 116,32 ; 122,55 ; 131,5$; 132,$55 ; 146,12 ; 147,56$. Anal. Calcd. para $\mathrm{C}_{10} \mathrm{H}_{6} \mathrm{~N}_{2} \mathrm{O}_{2} ; \mathrm{C} 64,51 \%$, $\mathrm{H} 3,23 \%$, N15,05\%, encontrado C63,87\%, H3,21\%, N14,86\%.

\section{Ácido 5,6-metilenodioxindol-3-il-metanóico (IX)}

3-ciano-5,6-metilenodioxindol (1,0 g; 5,3 mmol) em solução aquosa de hidróxido de sódio (30-40\%, 5,0 mL) foi refluxado durante $3 \mathrm{~h}$. Após resfriamento, a mistura foi diluída com água destilada $(5 \mathrm{~mL})$ e acidificada a pH 5,0 com ácido clorídrico (15\%). O produto foi isolado por filtração a vácuo, lavado com água e secado em estufa a vácuo, fornecendo o produto desejado em $75 \%$ de rendimento. Produto analiticamente puro foi obtido mediante recristalização em solução alcalina e posterior acidificação; pf = 237,1-239,0 ${ }^{\circ} \mathrm{C}$; IV (KBr): $v_{\max } / \mathrm{cm}^{-1}, 3437(\mathrm{NH}), 2908(\mathrm{OH}), 1678$ (CO) da carbonila e 1307 (COC); RMN ${ }^{1} \mathrm{H}(200 \mathrm{MHz}$, Acetona-d $)$ $\delta 3,65(\mathrm{~s}, 1 \mathrm{H}, \mathrm{OH}) 5,98(\mathrm{~s}, 2 \mathrm{H}), 6,98(\mathrm{~s}, 1 \mathrm{H}), 7,37(\mathrm{~s}, 1 \mathrm{H}), 7,99(\mathrm{~s}$, $1 \mathrm{H}), 11,67$ (s,1H, NH); RMN ${ }^{13} \mathrm{C}(50 \mathrm{MHz} \text {, Acetona-d })_{6} \delta$ 98,023; 
104,$25 ; 105,7 ; 113,025 ; 125,4 ; 135,13 ; 136,32 ; 148,78 ; 149,62 ;$ 171,27. Anal. Calcd. para $\mathrm{C}_{10} \mathrm{H}_{7} \mathrm{NO}_{4} ; \mathrm{C} 58,53 \%, \mathrm{H} 3,41 \%, \mathrm{~N} 6,82 \%$, encontrado $\mathrm{C} 59,10 \%, \mathrm{H} 3,39 \%$, N6,91\%.

\section{Testes de promoção de crescimento de radículas}

Todos os testes realizados são específicos para determinação da atividade reguladora de crescimento vegetal de auxinas.

Os ensaios para avaliação da promoção de crescimento de radículas foram conduzidos com sementes de Lactuca sativa variedade Grand Rapids (alface crespa), Cucumbis sativus (pepino) e Raphanus sativus (rabanete). As soluções do ácido 5,6metilenodioxindol-3-il-metanóico (IX) foram preparadas nas concentrações de $10^{-3}$ a $10^{-9} \mathrm{M}$ utilizando acetona como solvente. Os ensaios foram realizados em placas de Petri esterilizadas, sendo que para cada concentração utilizou-se 1 placa contendo 4 discos de papel filtro. Em cada disco de papel foi adicionado $1 \mathrm{~mL}$ de solução nas diferentes concentrações, sendo o solvente (acetona) evaporado antes da adição de $1,5 \mathrm{~mL}$ de Tween $80(0,01 \%)$, seguida da inoculação de 50 (alface) ou 20 (pepino ou rabanete) sementes em cada disco, num total de 200 ou 80 sementes em cada placa respectivamente. As sementes antes de serem inoculadas foram submetidas ao processo de assepsia em hipoclorito de sódio $40 \%$, etanol $70 \%$ e água destilada. As placas foram incubadas em câmara de germinação, com temperatura controlada a $25 \pm 2{ }^{\circ} \mathrm{C}$ e foto período de $16 \mathrm{~h} / \mathrm{luz}$ durante 5 dias sendo distribuídas ao acaso. No quinto dia após a inoculação das sementes foi realizada a coleta de dados, onde foram determinados os comprimentos em milímetros das radículas. Como controle foi utilizado ensaio similar, empregando-se somente acetona. Os dados foram tratados estatisticamente utilizando-se o teste de Tuckey a 5\% de probabilidade (statgraf).

\section{Bioteste de pecíolos em Phaseolus vulgaris (feijão de vagem)}

Investigações realizadas no Instituto Boice Thompsom de Nova York, por volta de 1940, estabeleceram que o 2,4-D em altas concentrações e algumas outras auxinas sintéticas são eficazes como herbicidas. A popularidade destes compostos baseia-se na elevada fitoxidade, baixo custo e seletividade, já que afetam somente ervas daninhas dicotiledôneas ${ }^{13,14}$.

O ácido 5,6-metilenodioxindol-3-il-metanóico (IX) foi submetido ao bioteste de pecíolos. Foram empregados também água/acetona e o ácido 2,4-diclorofenoxiacético (2,4-D) como padrão. Os compostos IX e 2,4-D foram testados nas concentrações de 25, 50 e 100 ppm. No preparo de cada solução foi empregada acetona como solvente.

As sementes de Phaseolus vulgaris foram inoculadas em placas de Petri sobre discos de papel filtro molhados com água destilada. As placas de Petri foram incubadas em câmara de germinação com temperatura controlada de $25 \pm 2{ }^{\circ} \mathrm{C}$ e foto período de 16 h/luz durante 4 dias, sendo distribuídas ao acaso. As sementes germinadas foram transplantadas para vasos de polietileno, utilizando como substrato terra orgânica misturada com casca de arroz. As plantas foram mantidas em casa de vegetação com umidade e ventilação controlada durante 10 a 15 dias.

As peças em "Y" foram colocadas em placas de Petri (1 peça por placa), com $5 \mathrm{~mL}$ de solução conforme os tratamentos: água/acetona, ácido 2,4-dicloro-fenoxiacético e o composto a ser avaliado. As plantas foram separadas por tratamento, sendo que cada um foi constituído de 15 a 20 exemplares. As placas foram mantidas em câmara de germinação com temperatura controlada a $25 \pm 2{ }^{\circ} \mathrm{C}$ e foto período de $16 \mathrm{~h} /$ luz durante $24 \mathrm{~h}$, sendo distribuídas ao acaso. Após este período desenhou-se o contorno de cada peça, mediram-se os ângulos entre os pecíolos e calculou-se a porcentagem de variação em relação à média dos ângulos iniciais para cada tratamento. Os dados do ensaio foram tratados estatisticamente pelo Excel, de acordo com o intervalo de confiança obtido da média das variações angulares.

\section{RESULTADOS E DISCUSSÃO}

A metodologia geral de síntese adotada para o núcleo 5,6metilenodioxindol (VI) foi a mesma empregada com sucesso na preparação do ácido 5,6-metilenodioxindol-3-il-acético (II) ${ }^{12}$.

O Esquema 1 apresenta a rota sintética empregada na obtenção da molécula alvo IX. A metodologia global é constituída de 6 etapas, podendo ser agrupadas em ciclização redutiva, para construção do anel indólico, e carboxilação seletiva, para funcionalização da posição- $3^{15-30}$.

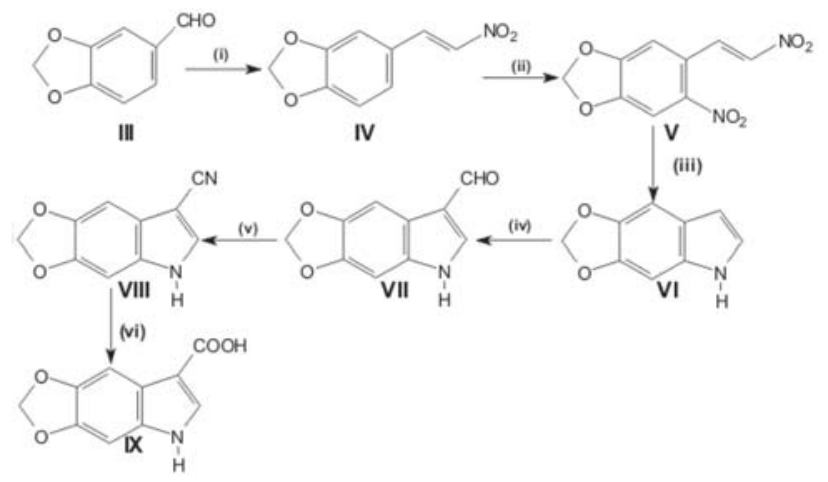

Esquema 1. (i) $\mathrm{CH}_{3} \mathrm{NO}_{2}, \mathrm{AcOH}, \mathrm{NH}_{4} \mathrm{OAc}$, refluxo (ii) $\mathrm{HNO}_{3}, \mathrm{AcOH}, \mathrm{O}^{\circ} \mathrm{C}$ (iii) Sílica gel 60, $\mathrm{Fe}, \mathrm{AcOH}$, benzeno, cicloexano, refluxo ou $\mathrm{Pd} / \mathrm{C} 10 \%, \mathrm{EtOH}$ absoluto, cicloexano, refluxo (iv) $\mathrm{POCl}_{3} \mathrm{DMF}, \mathrm{NaOH}$ (v) $\mathrm{DMF}, \mathrm{NH}_{2} \mathrm{OH} . \mathrm{HCl}$, (vi) $\mathrm{NaOH} 35 \%, \mathrm{HCl} 20 \%$

Dentre as rotas disponíveis no trabalho, ciclização redutiva e inserção por nitreno, optou-se pela primeira por permitir reações em maior escala e exigir uma etapa a menos que a construção do anel indólico através da inserção via nitreno.

\section{Ciclização redutiva}

Esta inicia-se com a reação de condensação do piperonal (III) com nitrometano em meio de ácido acético e acetato de amônio durante $4 \mathrm{~h}$ sob aquecimento. A reação é favorecida pela presença de uma base de Lewis que atua desprotonando o nitrometano, tornando-o mais nucleofílico. A reação processa-se por um ataque nucleofílico à carbonila, seguido de desidratação. O produto IV foi obtido com rendimento satisfatório de $74 \%$, sendo o seu ponto de fusão compatível com o da literatura. O produto também apresentou elevado grau de pureza, sendo utilizado sem purificação prévia.

$O$-nitro-3,4-metilenodioxi- $\beta$-nitroestireno (V) foi preparado a partir de (IV) através de uma reação clássica de nitração, que pôde ser realizada em condições brandas dada a reatividade do composto frente à substituição eletrofílica aromática. A reação apresentou-se altamente regiosseletiva, fornecendo o produto puro desejado em rendimento superior a $90 \%$ após cristalização em etanol. Fatores eletrônicos e estéreos podem ser invocados para justificar o resultado obtido.

A etapa crítica, qual seja, a redução parcial dos grupos nitro, ciclização e aromatização foi conduzida de duas formas distintas, de acordo com procedimentos da literatura.

A condução da reação de acordo com o procedimento descrito por Sinhababu e colaboradores ${ }^{19}$ permitiu a obtenção do composto 
VI em rendimento de $68 \%$. Nesta metodologia o $o, \beta$-dinitroestireno V foi refluxado na presença de sílica gel 60 para cromatografia em coluna, ferro em pó, ácido acético glacial, benzeno e cicloexano como fonte de hidrogênio. Produto analiticamente puro foi preparado pela cristalização em n-hexano.

Alternativamente, investigou-se a reação de ciclização redutiva empregando o método de Fukuyama ${ }^{20}$ que substitui ferro por $\mathrm{Pd} / \mathrm{C}$ e não utiliza ácido acético. $\mathrm{O}$ sólido escuro isolado foi purificado por cromatografia em coluna, fornecendo o indol VI puro em baixo rendimento, apenas $17 \%$.

Mediante análise espectroscópica de $\mathrm{RMN}$ de ${ }^{1} \mathrm{H}$ foi possível detectar $2 \mathrm{H}$ metilênicos, $4 \mathrm{H}$ aromáticos e o grupo N-H (sinal largo). A análise de ${ }^{13} \mathrm{C}$ apresentou 9 carbonos na região característica de aromáticos e de carbonos ligados a átomos eletronegativos.

\section{Carboxilação seletiva}

A carboxilação direta na posição-3 do anel indólico pode ser realizada de forma eficiente e seletiva adotando-se a estratégia sintética que emprega organometálicos e troca metal-halogênio. Entretanto, optou-se por metodologia que explora a substituição aromática eletrofílica de sistemas $\pi$-excessivos, por permitir a síntese de precursores com atividade potencial no campo dos reguladores de crescimento vegetal. Conforme apresentado no Esquema 1, grupos formil e ciano são considerados nas rotas biossintéticas da auxina AIA.

A reação de Vilsmeier-Haack é bastante utilizada na formilação de anéis aromáticos e baseia-se no emprego de tricloreto de fosforila e $N, N$-dimetilformamida como agente de formilação.

Nesta reação a espécie altamente eletrofílica, cloro-imínio, é gerada in situ. A cloroamina formada na reação de substituição é hidrolizada ao aldeído VII em meio alcalino. A reação é altamente regiosseletiva, por apresentar o anel pirrólico uma densidade eletrônica muito superior ao anel benzênico, e a posição-2 formar um estado de transição mais energético que o correspondente na posição-3. Portanto, o 5,6-metilenodioxindol-3-il-formaldeído (VII) foi isolado em rendimento satisfatório de $74 \%$.

Este composto foi caracterizado espectroscopicamente, apresentando no IV uma absorção em $1632 \mathrm{~cm}^{-1}$, própria de carbonila de aldeído aromático. Este mesmo grupo foi detectado por RMN de ${ }^{1} \mathrm{H}$, juntamente com 5 outros sinais, todos singletos. $\mathrm{Na}$ análise por ${ }^{13} \mathrm{C}$ o carbono formila ocorre caracteristicamente em 185,24 ppm, sendo acompanhado de mais 9 sinais, compatíveis com a estrutura proposta.

A conversão do grupo formila a ciano foi conduzida via oxima. A adição nucleofílica seguida de eliminação e a desidratação como etapa final requereram temperatura superior a $120{ }^{\circ} \mathrm{C}$. O produto VIII foi conseguido com rendimento de $84 \%$ após otimização das condições reacionais.

O espectro no IV apresentou a banda característica de deformação axial do grupo ciano em $2218 \mathrm{~cm}^{-1}$. A análise de RMN de ${ }^{1} \mathrm{H}$ apresentou um sinal largo em aproximadamente $11 \mathrm{ppm}$ referente ao grupo $\mathrm{N}-\mathrm{H}$ e 3 outros singletos correspondendo a $5 \mathrm{H}$. O espectro de ${ }^{13} \mathrm{C}$ apresentou todos os 10 carbonos, dos quais, 6 quaternários.

Finalmente, a molécula alvo, o ácido 5,6-metilenodioxindol3-il-metanóico (IX), foi obtida mediante hidrólise alcalina de VIII com rendimento satisfatório.

O grupamento carboxílico foi caracterizado por IV, apresentando as absorções referentes às deformações axiais $\mathrm{O}-\mathrm{H}$ e $\mathrm{C}=\mathrm{O}$.

A análise de RMN de ${ }^{1} \mathrm{H}$ apresentou dois sinais largos, 11,67 e 3,65 ppm, referentes aos dois prótons ácidos (um do ácido e outro do grupo amino) presentes na molécula proposta. Adicionalmente, os prótons metilênicos em 5,98 ppm e 3 prótons aromáticos (singletos) entre 6,98 e 7,79 ppm. O espectro de ${ }^{13} \mathrm{C}$ apresentou de forma previsível todos os 10 carbonos, dos quais, 6 quaternários.

\section{Promoção de crescimento de radículas}

A avaliação da promoção de crescimento de radícula foi realizada através de ensaios biológicos in vitro e baseia-se na medida do comprimento das radículas.

Objetivando avaliar a atividade reguladora de crescimento vegetal do composto IX, foram conduzidos ensaios utilizando-se como material vegetal sementes de Lactuca sativa variedade Grand Rapids (alface crespa), Cucumbis sativus (pepino) e Raphanus sativus (rabanete).

Nos experimentos conduzidos com Lactuca sativa, sementes submetidas à concentração $10^{-8} \mathrm{M}$ apresentaram a maior média de comprimento de radícula, $16,55 \mathrm{~mm}$, seguida das concentrações $10^{-6} \mathrm{e}$ $10^{-5} \mathrm{M}$ com 15,20 e $13,00 \mathrm{~mm}$, respectivamente. Sementes submetidas à suplementação de $10^{-7} \mathrm{M}$ apresentaram a menor média, 7,15 $\mathrm{mm}$, conforme mostra a Figura 1. Foram observadas leves variações nos comprimentos médios de radícula, não sendo possível, observar diferença estatística significativa entre as médias.

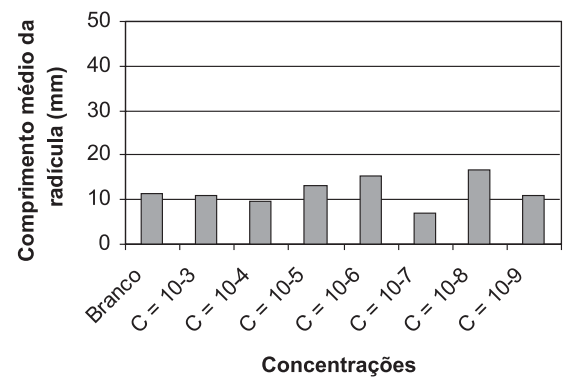

Figura 1. Efeito do composto $\mathbf{I X}$ no comprimento médio de radícula de sementes germinadas de Lactuca sativa (alface crespa)

Sementes de pepino submetidas à suplementação de $10^{-5} \mathrm{M}$ apresentaram a maior média de comprimento de radícula, 44,75 $\mathrm{mm}$, seguida das concentrações de $10^{-4}$ e $10^{-9} \mathrm{M}$, com médias de 39,25 e $38,40 \mathrm{~mm}$, respectivamente, com o ensaio controle (branco) apresentando média de 38,40 mm (Figura 2).

Na Figura 2 é possível observar variações nos comprimentos médios de radícula, não havendo, entretanto, diferença estatística significativa entre as médias, quando sementes de Cucumbis sativus (pepino) foram tratadas com diferentes concentrações.

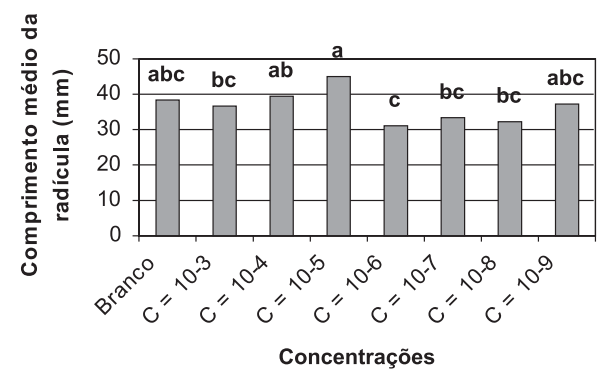

Figura 2. Efeito do composto IX no comprimento médio de radícula de sementes germinadas de Cucumbis sativus (pepino). As letras minúsculas representam o teste de médias - Tukey, 5\%

O comprimento médio de radícula de sementes germinadas de Raphanus sativus (rabanete) não se mostrou significativo. Sementes submetidas às concentrações de $10^{-6}, 10^{-8}$ e $10^{-9} \mathrm{M}$ apresentaram as médias mais altas, 32,10; 31,05 e 30,00 mm, respectivamente, sendo a média do controle de $30,00 \mathrm{~mm}$. Sementes suplementadas com IX na concentração de $10^{-4} \mathrm{M}$ apresentaram a menor média de comprimento de radícula, 24,05 mm, como mostrado na Figura 3. 


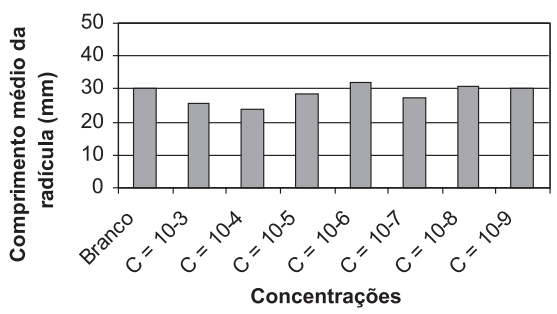

Figura 3. Efeito do composto IX no comprimento médio de radículas de sementes germinadas de Raphanus sativus (rabanete)

\section{Ensaios do bioteste de pecíolos}

Nos testes conduzidos com o composto IX foi possível observar que os pecíolos tratados na concentração de 25 ppm apresentaram variação na porcentagem dos ângulos inicial e final inferior quando comparado ao padrão 2,4-D. Já as concentrações de 50 e 100 ppm o fechamento dos ângulos internos das peças em "Y" foram levemente superiores (Figura 4). Entretanto, os dois compostos não apresentaram diferença estatística significativa entre si, assim, considera-se o composto IX tendo potencial propriedade reguladora de crescimento vegetal, pois sua atividade foi bastante semelhante ao padrão 2,4-D.

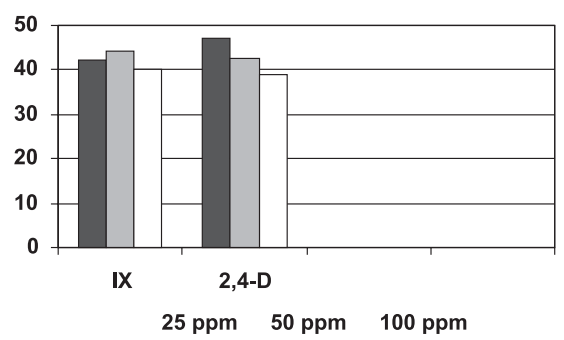

Figura 4. Efeito dos compostos IX e 2,4-D em porcentagem no fechamento do ângulo interno de peças em " $Y$ " com plantas Phaseolus vulgaris (feijão de vagem)

\section{CONCLUSÕES}

A obtenção do núcleo 5,6-metilenodioxindol (VI) via ciclização redutiva do $o, \beta$-dinitroestireno foi conduzida conforme procedimento da literatura. Este empregou piperonal como material de partida, fornecendo o produto desejado em 3 etapas com rendimento global de $46 \%$.

A síntese do ácido 5,6-metilenodioxindol-3-il-metanóico (IX) foi conduzida a partir de VI em 3 etapas, nominalmente: formilação, formação de nitrila via oxima e hidrólise alcalina. $\mathrm{O}$ rendimento global do procedimento de carboxilação seletiva foi de $40 \%$.

Os compostos ácido 5,6-metilenodioxindol-3-il-metanóico (IX) e seu precursor VIII são compostos inéditos.

As substâncias sintetizadas foram caracterizadas por análises no IV, RMN ${ }^{1} \mathrm{H} \mathrm{e}{ }^{13} \mathrm{C}$, espectrometria de massa, análise elementar e ponto de fusão, apresentando dados compatíveis com as estruturas propostas.

Os ensaios conduzidos com o ácido 5,6-metilenodioxindol-3il-metanóico (IX) para a avaliação da atividade reguladora de crescimento vegetal quanto a promoção de crescimento de radículas em sementes germinadas de Lactuca sativa, Cucumbis sativus e Raphanus sativus não foram muito expressivos, pois as médias dos tamanhos das raízes ficaram muito próximas entre si nas várias concentrações não apresentando diferença estatística significativa.

No ensaio do bioteste de pecíolos empregando plantas de Phaseolus vulgaris, o composto IX apresentou atividade superior ao padrão 2,4-D nas concentrações de 50 e 100 ppm, e inferior na concentração de 25 ppm.

Isto nos deixa otimistas quanto ao seu emprego como regulador de crescimento vegetal; embora, ensaios complementares de enraizamento caulinar e de embriogênese somática sejam necessários para estabelecer o potencial desse composto como regulador de crescimento vegetal.

\section{AGRADECIMENTOS}

Ao Prof. Dr. R. A. Rebelo e a Profa. Dra. F. A. F. da Rosa pela orientação e apoio; ao Departamento de Química da FURB pela infraestrutura disponibilizada; à Prof ${ }^{a}$. R. Pescador, do Departamento de Ciências Naturais da FURB, pela orientação nas atividades laboratoriais em geral e ao Departamento de Química da Universidade Federal de Santa Catarina, pelas análises espectroscópicas.

\section{REFERÊNCIAS}

1. Raven, P. H.: Evert, R. F.; Eichorn, S. E,; Biologia Vegetal, Regulando o Crescimento e do Desenvolvimento: Os Hormônios Vegetais, Ed. Guanabara Koogan S. A: Rio de Janeiro, 2001, cap. 26.

2. Rosa, A. F. F.; Rebelo, A. R.; Nascimento, M. G.; J. Braz. Chem. Soc. 2003, $11,15$.

3. Perrin, D. D.; Armarego, W. L. F.; Purification of Laboratory Chemicals Pergamon Press: Oxford, England, 1988.

4. Costa, P. R. R.; Quim. Nova 2000, 23, 357.

5. Costa, P. R. R.; Barreiro, E. J.; Barros, P. R. V. R.; Queiroz, W. M.; J. Chem. Res. 1982, 1142.

6. Coelho, F. A. S.; Costa, P. R. R.; Farias, F. M. C.; Barreiro, E. J.; Quim. Nova 1984, 7, 113.

7. Barreiro, E. J.; Fraga. C. A. M.; Quim. Nova 1999, 22, 744.

8. Pereira, E. F. R.; Pereira, N. A.; Lima, M. E. F.; Coelho, F. A. S.; Barreiro, E. J.; J. Braz. Med. Biol. Res, 1989, 1415.

9. Barreiro, E. J.; Costa, P. R. R.; Mello, R. T.; Barros, P. R. R. V.; An. Acad. Braz. Ciênc. 1981, 65, 67.

10. Barreiro, E. J.: Fraga, C. A. M.; Química Medicinal: Razões Moleculares da Ação dos Fármacos, Artmed Ed. S. A: Porto Alegre, 2001.

11. Dallacker, F.; Bernabei, D.; Monatsh. Chem. 1967, 98, 785.

12. Rosa, F. A. F.; Tese de Doutorado, Universidade Federal de Santa Catarina, Brasil, 2002.

13. George, E. F.; Plant Propagation by Tissue Culture, Part1: The Technology, 2ed., Exegetics Limited: Inglaterra, 1993, p. 420-434.

14. Miller, E. V.; Fisiologia Vegetal, Editorial Hispano Americana: México, 1967, p. 205, 214.

15. Sundberg, R. J.; J. Org. Chem. 1968, 2, 487.

16. Cadogan, J. I. G.; Cameron-wood, M.; Mackie, R. K.; Searle, R. J. G.; J. Chem. Soc. 1965, 4831.

17. Kraus, G. A.; Selvakumar, N.; Synlett 1998, 845.

18. Huebner, C, F.; Troxell, H. A.; Schroeder, D. C.; J. Am. Chem. Soc 1953, $75,5887$.

19. Sinhababu, A. K.; Borchardt, R. T.; J. Org. Chem. 1983, 48, 3347.

20. Fukuyama, A. K.; Iwatsuki, C.; Kodama, M.; Ochi, M.; Kataoka, K.; Tetrahedron 1998, 54, 10007.

21. Fukuyama. T.; Chen, X.; J. Am. Chem. Soc. 1994, 116, 3125.

22. Shingo, M.; Masato, K.; Patent Abstracts of Japan 62077366 A 1987.

23. Shingo, M.; Masato, K.; Patent Abstracts of Japan 01228962 A 1989.

24. Gilchrist, T. L.; Heterocyclic Chemistry, Longman Scientific \& Technical: New York, 1985, cap. 6.

25. Joule, J. A.; Smith, G. F.; Heterocyclic Chemistry, $2^{\text {nd }}$ ed., Var Nostrand Reinhold (international): London, 1978, cap. 21.

26. Joule, J. A.; Mis, K. Smith G. F.; Heterocyclic Chemistry, $3^{\text {rd }}$ ed., Chapmann \& Hall: Londres, 1995, cap. 17.

27. Gribble, G. W.; J. Chem. Soc., Perkin Trans. I 2000, 1045.

28. Elderfield, R. C.; Heterocyclic Compounds, John Wiley \& Sons, Inc: New York, 1952, cap. 1.

29. Paquette, L. A.; Modern Heterocyclic Chemistry, W. A. Benjamin, Inc: Nova York, 1968, cap. 5.

30. Moody, C. J.; Swann, E.; Synlett 1998, 135. 